\title{
Optimization of Semiconductor Processing Water Management Strategy
}

\author{
B. J. Wang ${ }^{1}$, L. L. Lee ${ }^{2}$, C. H. Chen ${ }^{2}$, C. N. Chang ${ }^{2 *}$ and A. C. Chao ${ }^{3}$ \\ ${ }^{1}$ Graduate Institute of Business Administration, Tunghai University, Box 5-819, Taichung City, Taiwan 407, Taiwan \\ ${ }^{2}$ Department Institute of Environmental Science, Tunghai University, Taichung City, Taiwan 407, Taiwan \\ ${ }^{3}$ Department of Civil Construction and Environmental Engineering, North Carolina State University Raleigh, \\ North Carolina, USA
}

\begin{abstract}
In this study, regression and cost analyses based on both mass balance and cost are applied to optimize the recycling of processing water for a 6-inch semiconductor wafer manufacturing plant. The analyses can also be applied to obtain the optimum reuse rate if the plant is expanded to produce 8-inch or 12-inch wafers. A mass balance diagram is first developed for three systems: processing system, wastewater system and recovery system. The information contained in the diagram is then modified to include the total costs of various water treatment unit processes for analyzing the costs for the above three systems. These costs are then used as the bases for optimizing the water recycling operation. Regression analyses to show the influence of various parameters e.g. the recovery rate of processing water, water usage, operation and maintenance costs and quantities of pollutants, on the operation costs of the above systems, have also been carried out using the Statistical Package for Social Science (SPSS) software. The resulting optimum recovery rates are $77 \%$ for the 6 -inch wafer plant, $80 \%$ for the 8 -inch wafer plant and $86 \%$ for the 12 -inch wafer plant. Thus, when the wafer size is upgraded, the water-recycling rate should also be raised for achieving the most cost-effective water reuse. The analyses also evaluate the water recycling practice for various assumed unit water costs. Using the 6-inch wafer plant as an example, the optimum water-recycling rate should be raised to $74 \%, 77 \%, 78 \%, 81 \%$ and $84 \%$ for water costing $\$ 0.20$, $\$ 0.36, \$ 0.51$, $\$ 0.71$ and $\$ 1.00$ per tons, respectively. Applying the cost analysis methods proposed in this study, the optimum water-recycling rate could be determined in response to variations of wafer manufacturing operations. Additionally, the $\mathrm{r}$ regression analysis results have demonstrated that the wafer size, costs of the three aforementioned systems, and water cost significantly influence the optimized recycling rate of semiconductor processing water.
\end{abstract}

Keywords: Cost analyses, optimum recycling of processing water, optimum water reuse rate, regression analyses, semiconductor wafer manufacturing plant

\section{Introduction}

Semiconductor wafers are important parts of electronic products. The increasing global demand of micro-integrated circuits greatly stimulates the production of wafers at an average $16 \%$ annual growth over last decade with estimated sales of $\$ 140$ billion in 2000 (World Semiconductor Trade Statistics, 1998). Taiwan is an important semiconductor- manufacturing base in the world with $90 \%$ or more in IC production that contributes to $73 \%$ of the annual global wafer production. Both wafer production and IC packaging in Taiwan are ranked number one in the world. There are four 12-inch, twenty-two 8-inch, eight 6-inch, five 5-inch, and one 4-inch wafer manufacturing plants currently operated in Taiwan (Ministry of Economic Affairs, Bureau of Industrial Development, Taiwan, ROC, 2001).

All unit processes of semiconductor manufacturing need water for processing (e.g., plating water), cleaning, and/or cooling (You et al., 1999) in photolithography, oxidation, etching, doping, and planarization. Table 1 shows statistical

\footnotetext{
* Corresponding author: cnchang@mail.thu.edu.tw
}

data on the sources of different categories of water usage for IC industries in Taiwan. The processing water is seen to constitute a major portion of the total water consumption. Approximate $70 \%$ of the total water demand needs to be ultra-pure for cleaning silicon wafers. Hence, providing processing water to meet both quantity and quality requirements are a serious challenge to local semiconductor industries.

With improved technology, larger wafers with smaller bandwidth will require more ultra-pure water. In 2000, the global daily water demand of ultra-pure water for wafer cleaning was 1.5 million tons (Lu, 1998). In Taiwan alone, 40 million tons of ultra-pure water are needed annually and the annual demand is expected to increase to 78 million tons in 2006. The discharge of processing wastewater was 24 million tons per year in 2000 and will be 44 million tons per year in 2006 (Chen, 2002).

After recovering from a recession period, the semiconductor industry in Taiwan is planning to build several new 12-inch wafer-manufacturing plants. With increasing wafer diameters, the water consumption per unit product will increase accordingly, and so does the production cost. When the 6-inch wafer operation is upgraded to 8-inch, the demand 
Table 1. Analysis of Different Categories of Water Consumptions for the Various Wafer Companies (Taiwan, Ministry of Economic Affairs, Bureau of Industrial Development, 2003)

\begin{tabular}{llllll}
\hline Companies & $\begin{array}{l}\text { Indirect Cooling } \\
\text { water (\%) }\end{array}$ & $\begin{array}{l}\text { Air conditioning } \\
\text { water (\%) }\end{array}$ & Processing water (\%) & Sanitary water (\%) & Others (\%) \\
\hline 5-inch Wafer Semi-Conductor Material & 3.25 & 15.32 & 69.75 & 3.06 & 8.62 \\
8-inch Wafer Semi-Conductor Material & 8.20 & 4.08 & 74.94 & 4.30 & 8.49 \\
6-inch Wafer Manufacturing & 10.76 & 4.72 & 71.44 & 1.90 & 11.18 \\
8-inch Wafer Manufacturing & 11.44 & 2.79 & 57.56 & 0.95 & 27.26 \\
12-inch Wafer Manufacturing & 7.11 & 4.05 & 46.16 & 1.26 & 41.42 \\
\hline
\end{tabular}

of ultra-pure processing water is raised from 2 tons to 4.5 tons per slice of wafer in the U.S. Using the wet etching process, upgrading the 6-inch wafer process to 8-inch process in Taiwan will increase the water cost from $13 \%$ to $32 \%$ of the total production cost (Shi et al., 2003). The water consumption for 12-inch wafer is estimated to increase 2 to 3 times that for 8-inch wafer. The water consumption for semiconductor plants in Taiwan is generally lower than that reported by U.S. chip manufactures (DeGenova and Shadman, 1997) indicating that local manufactures in Taiwan have already practiced some water conservation and wastewater reuse measures.

The total water consumed by IC industries in Taiwan increased from 60,987 CMD in the $3^{\text {rd }}$ quarter of 2001 to 142,937 CMD in 2004 and ultimately to an estimated 152,082 CMD in 2005 (Figure 1). The increasing industrial processing water demand and limited available water resources are expected to keep a tight rein on future development of wafer manufacturing industries in Taiwan. Hence, recovery and reuse of water resources to achieve water savings has become an important issue for the semiconductor industry (Golden, 2000).

Currently, the Taiwan (ROC) Hsinchu Science Park requires that existing semiconductor plants must recycling $45 \%$ processing wastewater and newly established plants in the future must achieve $70 \%$ recovery of processing water. The major portion of recycling wastewater comes from six wastewater streams: (1) acidic wastewater, (2) wafer polishing wastewater, (3) RO concentrates from the ultra-pure water system, (4) cooling tower discharge and air conditioning condensate, (5) recycling processing water, and (6) recycling processing wastewater (Lin, 1999). Very few semiconductor plants use advanced methods e.g. ion exchange and reverse osmosis, to treat the recovered discharge. Instead, the current water reuse practice in most semiconductor plants is to use the recovered processing wastewater as cooling water without much treatment (Michael, 1996; Thomas and Thomas, 1996). In the future, high water cost or limited water supply will make it economically attractive to treat the recover discharge to meet higher standards so that the treated effluent can be used in processing instead of cooling.

Technically, the current water technology is available to treat the recycling discharges to any degree of quality so that the recycling water can be used in the various semiconductor processes. The cost associated with the treatment may vary from almost zero for no treatment to highest for advanced treatment such as RO (reverse osmosis). The cost-effectiveness of water recycling is dependent on the percentage of recycling water, the benefit and the cost associated with water recycling. The current water-recycling rate is estimated based only on mass balance consideration. When the overall water recovery rate changes, the component unit operations and processes may be subject to variations in quantity and quality of both the influent and effluent streams, thus, the associated unit production cost and the total production coat will also change. Additionally, higher recycling rate of processing water in most cases may require more capital investment as well as higher operation and maintenance costs on advanced treatment so that the recycling discharges can be used as processing water instead of cooling water. Finding the recycling rate that will result in the most cost-effective operation of the semiconductor production is crucial to reducing the overall production cost and to providing an incentive for the industry to implement water saving practices. Thus, the recycling rate must be based on considerations on both mass balance and costs involved to obtain a true cost-effective recycling rate.

The objective of this study is to determine the optimal water processing recycling rate based on both mass balance and cost analyses using the Statistical Package for Social Science (SPSS) software to assist in completing the regression analyses. The analyses will encompass the influence of water costs on the most cost-effective wastewater-recycling rate and the associated costs for a typical semiconductor plant as well as for hypothetical plants producing wafers of various sizes As shown in Table 2, nearly all plants in Taiwan have not reached the target recovery rate as required by regulatory agencies. Hence, the procedures and/or results of finding the real cost-effectiveness water recycling rate as undertaken in this study will assist those plants in achieving cost-effective water reuse in addition to meeting future legal water reuse requirements.

\section{Methodology}

A typical new medium-size semiconductor plant was selected for carrying out this study. It is located in Hsinchu Science Park, Taiwan, employing 1500 workers to produce IC chips and 6-inch wafers for use in communication equipment, 


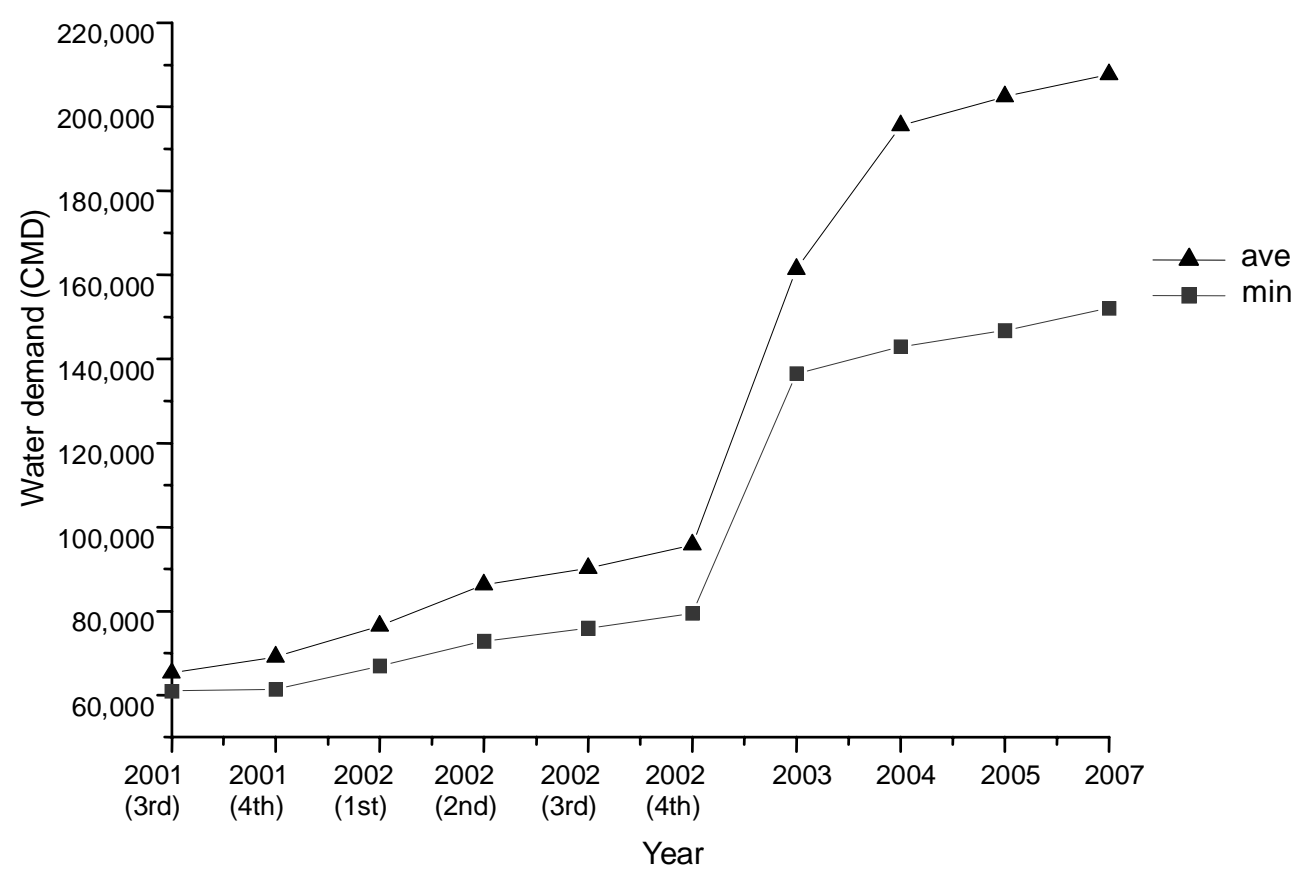

Figure 1. Past and Future Water Demand for IC Industry in Taiwan (Taiwan, ROC, Ministry of Economic Affairs, Bureau of Industrial Development, 2003).

computers, electrical control devices, and numerous other electronic products. The plant, which is owned and operated by a domestic company that practices good management in pollution control, is currently recycling $66 \%$ of the effluent that is a little lower than the $70 \%$ level for new plants as specified by HsinChu Science Park.

Table 2. Current Water Recycling Status (Taiwan, Ministry of Economic Affairs, Bureau of Industrial Development, 2003)

\begin{tabular}{ll}
\hline Companies & Recycling rate (\%) \\
\hline 5-inch Wafer Semi-Conductor Material & 39.93 \\
8-inch Wafer Semi-Conductor Material & 35.89 \\
6-inch Wafer Manufacturing & 54.86 \\
8-inch Wafer Manufacturing & 70.77 \\
12-inch Wafer Manufacturing & 70.58 \\
\hline
\end{tabular}

The cost-effectiveness analyses are carried out in fours steps: (1) data collection, (2) mass balance and cost-analyses, (3) cost-effective analyses and (4) regression analyses (Figure 2). The model developed by Ramalho (1977) has been expanded to establish a water balance diagram for the IC processing operation for understanding the water usage and recycling potential of each unit. From the mass balance diagram, the unit operations and processes for implementing water reuse practice can then be identified. The relationship of mass balance between two related unit operations and the operating cost for each unit operation is first established. Subsequently, changes of the quality and quantity of the influent and effluent streams to the processing, wastewater treatment and recovery systems as well as the associated operating costs in response to variations of process water recycling ratio can be calculated using a spreadsheet program. An example spreadsheet calculation showing process water-recycling rates of 1 to $90 \%$ is shown in Table 3.

The total cost is then calculated based on the quantity and cost of component unit operations and processes. Using the assumed various water recycling ratios, the most costeffective recycling rate can be determined. Subsequently, the SPSS software is used to carry out regression analyses for analyzing the influence of the costs associated with the processing, wastewater treatment and recovery systems on the water recovery rate and to determine how significant the influence of water recycling rate is on the total cost. The SPSS is a commonly used computer software package to provide collinearity statistics with tolerance and variance inflation factor (VIF) for analyzing the multi-collinearity of variances. All parameters considered may not be collinear to result in meaningful regression analyses. Hence, prior to carrying out the regression analyses, collinear properties of all parameters need to be examined and verified. A Variance Inflation Factor (VIF) lower than 10 indicates that no significant relationship exist among the parameters and that the colinearity will not interfere with the regression analyses. The regression analysis results will include the $p$ and $\beta$ values 
Table 3. Spreadsheet Results Showing the Calculation of Total Cost at Different Process Water Recycling Rates and the Minimum Total Cost Is Obtained at 77\% Process Water Recycling Rate

\begin{tabular}{|c|c|c|c|c|c|c|c|c|c|}
\hline Process Water Recycle Rate & 0.01 & 0.10 & 0.20 & 0.30 & 0.40 & 0.50 & 0.70 & 0.77 & 0.90 \\
\hline Ultra-Pure System Flow (ton/day) & 2414 & 2414 & 2414 & 2414 & 2414 & 2414 & 2414 & 2414 & 2414 \\
\hline $\begin{array}{l}\text { Flow from the Ultra-Pure System to Process } \\
\text { (ton/day) }\end{array}$ & 1351.84 & 1351.84 & 1351.84 & 1351.84 & 1351.84 & 1351.84 & 1351.84 & 1351.84 & 1351.84 \\
\hline $\begin{array}{l}\text { Ultra-Pure System Recycle and Secondary } \\
\text { Water Usage Flow (ton/day) }\end{array}$ & 989.74 & 989.74 & 989.74 & 989.74 & 989.74 & 989.74 & 989.74 & 989.74 & 989.74 \\
\hline $\begin{array}{l}\text { Flow of Wastewater Discharged from the } \\
\text { Ultra-Pure Water System (ton/day) }\end{array}$ & 72.42 & 72.42 & 72.42 & 72.42 & 72.42 & 72.42 & 72.42 & 72.42 & 72.42 \\
\hline Ultra-Pure Recycle Water Flow (ton/day) & 440.43 & 440.43 & 440.43 & 440.43 & 440.43 & 440.43 & 440.43 & 440.43 & 440.43 \\
\hline $\begin{array}{l}\text { Flow from the Ultra-Pure System to } \\
\text { Secondary System (ton/day) }\end{array}$ & 549.31 & 549.31 & 549.31 & 549.31 & 549.31 & 549.31 & 549.31 & 549.31 & 549.31 \\
\hline Flow of Recycled Process Water (ton/day) & 13.52 & 135.18 & 270.37 & 405.55 & 540.74 & 675.92 & 946.29 & 1040.92 & 1216.66 \\
\hline $\begin{array}{l}\text { Influent Flow to the Ultra-Pure Water } \\
\text { System (ton/day) }\end{array}$ & 1960.05 & 1838.38 & 1703.20 & 1568.01 & 1432.83 & 1297.65 & 1027.28 & 932.65 & 756.91 \\
\hline Flow of Secondary Water Usage (ton/day) & 810 & 810 & 810 & 810 & 810 & 810 & 810 & 810 & 810 \\
\hline $\begin{array}{l}\text { Flow of Water Evaporated from Secondary } \\
\text { System (ton/day) }\end{array}$ & 330 & 330 & 330 & 330 & 330 & 330 & 330 & 330 & 330 \\
\hline $\begin{array}{l}\text { Flow of Wastewater Discharged from } \\
\text { Secondary System (ton/day) }\end{array}$ & 480 & 480 & 480 & 480 & 480 & 480 & 480 & 480 & 480 \\
\hline $\begin{array}{l}\text { Flow of Influent to the Secondary System } \\
\text { (ton/day) }\end{array}$ & 226.69 & 226.69 & 226.69 & 226.69 & 226.69 & 226.69 & 226.69 & 226.69 & 226.69 \\
\hline $\begin{array}{l}\text { Wastewater Flow Discharged from the } \\
\text { Wastewater Treatment System (ton/day) }\end{array}$ & 1338.32 & 1216.66 & 1081.47 & 946.29 & 811.10 & 675.92 & 405.55 & 310.92 & 135.18 \\
\hline $\begin{array}{l}\text { Flow of Total Wastewater Discharge } \\
\text { (ton/day) }\end{array}$ & 1890.74 & 1769.08 & 1633.89 & 1498.71 & 1363.52 & 1228.34 & 957.97 & 863.34 & 687.60 \\
\hline $\begin{array}{l}\text { Flow of Total Influent of Tap Water } \\
\text { (ton/day) }\end{array}$ & 2186.74 & 2065.08 & 1929.89 & 1794.71 & 1659.52 & 1524.34 & 1253.97 & 1159.34 & 983.60 \\
\hline Tap Water Unit Price (\$/ton) & 0.36 & 0.36 & 0.36 & 0.36 & 0.36 & 0.36 & 0.36 & 0.36 & 0.36 \\
\hline Daily Cost of Tap Water (\$/ton) & 780.98 & 737.53 & 689.25 & 640.97 & 592.69 & 544.41 & 447.85 & 414.05 & 351.29 \\
\hline Unit Cost of Ultra-Pure Water (\$/ton) & 1.93 & 1.93 & 1.93 & 1.93 & 1.93 & 1.93 & 1.93 & 1.93 & 1.93 \\
\hline Daily Cost of Ultra-Pure Water (\$/ton) & 2607.12 & 2607.12 & 2607.12 & 2607.12 & 2607.12 & 2607.12 & 2607.12 & 2607.12 & 2607.12 \\
\hline $\begin{array}{l}\text { Daily Quantity of Additional Pollutants in } \\
\text { Process (ton/day) }\end{array}$ & 1635.73 & 1635.73 & 1635.73 & 1635.73 & 1635.73 & 1635.73 & 1635.73 & 1635.73 & 1635.73 \\
\hline $\begin{array}{l}\text { Daily Quantity of Pollutants in Recycled } \\
\text { Processing (ton/day) }\end{array}$ & 16.36 & 163.57 & 327.15 & 490.72 & 654.29 & 817.86 & 1145.00 & 1259.51 & 1472.15 \\
\hline $\begin{array}{l}\text { Daily Quantity of Pollutants in the Recycled } \\
\text { Water through the Recycle System (ton/day) }\end{array}$ & 1.08 & 10.81 & 21.63 & 32.44 & 43.26 & 54.07 & 75.70 & 83.27 & 97.33 \\
\hline $\begin{array}{l}\text { Daily Quantity of Pollutants Discharged to } \\
\text { the Wastewater System (ton/day) }\end{array}$ & 1619.37 & 1472.15 & 1308.58 & 1145.00 & 981.44 & 817.86 & 490.72 & 376.22 & 163.57 \\
\hline $\begin{array}{l}\text { Daily Quantity of the Ultimate Pollutant } \\
\text { Discharge (ton/day) }\end{array}$ & 300 & 300 & 300 & 300 & 300 & 300 & 300 & 300 & 300 \\
\hline $\begin{array}{l}\text { Daily Quantity of Pollutants Removed in the } \\
\text { Wastewater System (ton/day) }\end{array}$ & 1319.37 & 1172.15 & 1008.58 & 845.00 & 581.44 & 517.86 & 190.72 & 76.22 & -136.43 \\
\hline $\begin{array}{l}\text { Daily Quantity of Pollutants Removed in the } \\
\text { Recycle System (ton/day) }\end{array}$ & 15.28 & 152.76 & 305.52 & 458.27 & 611.03 & 763.79 & 1069.30 & 1176.24 & 1374.62 \\
\hline Daily Cost of the Recycle System (\$/day) & 16.51 & 165.13 & 330.26 & 495.39 & 660.52 & 825.66 & 1155.92 & 1271.51 & 1486.18 \\
\hline $\begin{array}{l}\text { Daily Cost of the Wastewater Treatment } \\
\text { System (\$/day) }\end{array}$ & 1284.98 & 1122.17 & 942.63 & 765.09 & 590.57 & 420.87 & 115.26 & 36.06 & 79.88 \\
\hline Daily Charge for COD Discharge (\$/day) & 26.60 & 24.88 & 22.98 & 21.08 & 19.18 & 17.28 & 13.47 & 14.14 & 9.67 \\
\hline Daily Charge for SS Discharge (\$/day) & 33.30 & 31.16 & 28.78 & 26.40 & 24.02 & 21.64 & 16.87 & 15.21 & 12.11 \\
\hline $\begin{array}{l}\text { Basic Charge for Total Wastewater } \\
\text { Discharge in Hsinchu Science Park (\$/day) }\end{array}$ & 324.13 & 303.27 & 280.10 & 256.92 & 233.75 & 210.64 & 164.22 & 148.00 & 117.88 \\
\hline $\begin{array}{l}\text { Daily Sewage Charge in Hsinchu Science } \\
\text { Park (\$/day) }\end{array}$ & 384.03 & 359.32 & 331.86 & 304.40 & 276.94 & 249.49 & 194.57 & 175.35 & 139.66 \\
\hline Daily Cost of Water Supply (\$/day) & 3388.10 & 3344.65 & 3296.37 & 3248.09 & 3199.81 & 3151.53 & 3054.97 & 3021.17 & 2958.41 \\
\hline Daily Cost of Recycling System (\$/day) & 16.51 & 165.13 & 330.26 & 495.39 & 660.52 & 825.66 & 1155.92 & 1271.51 & 1486.18 \\
\hline Daily Cost of Wastewater Treatment (\$/day) & 1669.01 & 1481.49 & 1274.49 & 1069.49 & 867.51 & 670.36 & 309.84 & 211.41 & 219.55 \\
\hline Total Cost & 5073.62 & 4991.27 & 4901.12 & 4812.97 & 4727.85 & 4647.54 & 4520.72 & 4504.09 & 4664.13 \\
\hline
\end{tabular}


to indicate how two components are significantly related to each other. A low $p$ value indicates that two parameters are significant to each other, or the influence of one parameter on another parameter is significant while a low $\beta$ value shows that decrease reduction rate of the influence between two parameters. (Liu et al., 2003).

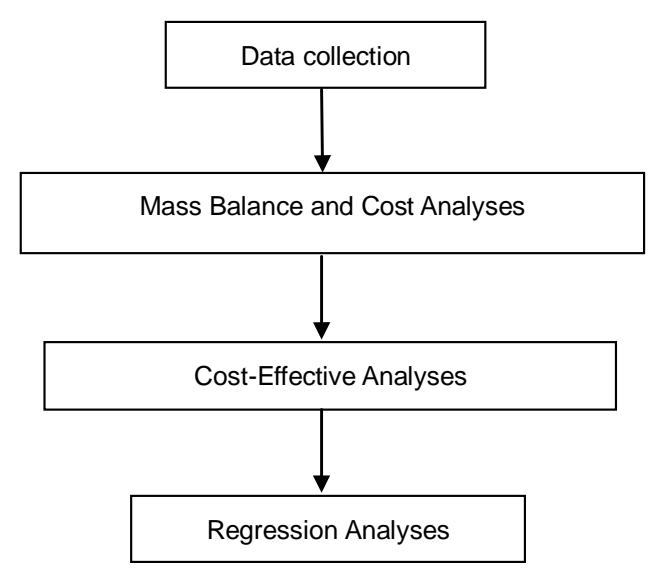

Figure 2. Flow-chart of this study.

\section{Results and Discussion}

\subsection{Establishing Mass Balance Diagram}

Figure 3 shows the mass balance of the selected plant operations developed using the expanded Ramalho model. Each block represents a unit operation or processes with marked quantities of influent and effluent. The in-plant influent to the ultra-pure system is fixed at 2,414 tons per day; implementing water recycling and reuse will reduce the external tap water influent quantity of 2,186 tons per day. All numbers shown in this diagram are based on an assumed $1 \%$ processing water recycling. If the processing water recycling rate and the influent quantity and quality are changed, the model will automatically re-calculate the quantity and quality mass balance of the influent and effluent streams for each unit operation. Although included and calculated in the model, the water quality information is not shown in Figure 3.

\subsection{The Optimal Process Water Recovery Rate}

\subsubsection{Evaluating Different Process Water Recovery Rate and Total Cost Analyses}

The water supply cost, wastewater treatment cost, recycling water treatment cost and their summation as the total cost for an assumed tap water cost of $\$ 0.36$ per ton are plotted versus the water reuse in Figure 4. While individual wastewater treatment cost and recycling water treatment cost may increase or decrease for higher water recycling rate, the total cost initial steady decreases initially to reach a minimum (Figure 4A) and then increases sharply (Figure 4B). At the water cost of $\$ 0.36$ per ton, a minimum total cost of $\$ 4,504$ per day is obtained when the process water recycling rate is $77 \%$. This is higher than the current average water recycling ratio of $66 \%$, thus proving that the selected semiconductor plant needs to raise the water recycling and reuse ratio above the legally required level in order to achieve a more costeffective operation.

\subsubsection{Influence of Tap Water Cost on the Optimal Water Recycling Rate}

The cost of external tap water is expected to increase in the future. This simulation study is also undertaken using different tap water cost levels and the results are shown in Figure 5A. All curves have similar variation pattern but the total cost is less for lower tap water cost. Additionally, as the water cost increases, the optimal water recycling rate is shifted toward higher water recycling rates. Figure $5 \mathrm{~B}$ has expanded water recycling rate scale to exaggerate the minimum water recycling rate. The curves show that the optimal water recycling rate should be increased in response to higher water cost, e.g. $74 \%$ for $\$ 0.20 /$ ton, $77 \%$ for $\$ 0.36 /$ ton, $78 \%$ for $\$ 0.51 /$ ton, $81 \%$ for $\$ 0.71 /$ ton, and $84 \%$ for $\$ 1.00 /$ ton.

\subsubsection{Comparison of the Influence of Water Recycling Rate on the Total Cost for 6-inch, 8-inch and 12-inch wafers}

Figure 6 shows the optimal water recovery rate for different wafer sizes. The results indicate that higher recovery rates are preferred for larger wafer diameters. Since the manufacturing of larger wafers needs more water consumption causing higher total cost (Shi, 2003), the cost associated with recycling the effluent discharge becomes relatively inexpensive leading to higher cost-effective recovery rate.

\subsection{Influence of the Costs of the Three Systems on Opti- mal Water Recovery}

The Variance Inflation Factor (VIF) of the parameter matrix (1.382) being much lower than 10 indicates that there exists no significant relationship among the parameters such that the parameter colinearity will not interfere with the regression analyses. The subsequent regression analysis results show that the water recycling rate is significant to influence the total processing cost because of the calculated $p$ value being smaller than 0.000 and $\beta$ value being $1.7301 \mathrm{E}-05$.

\subsection{Influence of Tap Water Cost on the Total Cost}

Regression analyses are performed to evaluate the influence of process water recycling on the total cost at different tap water prices, e.g. \$ 0.20, \$ 0.36, \$ 0.51, \$ 0.71 and \$ 1.00 per tons. As shown in Table 4, the $p$ value is less than 0.016 when the tap water cost of $\$ 0.71 /$ ton and 0.00 for $\$ 1.00 /$ ton. The smaller $p$ value indicates that at higher tap water cost the process water recycling rate becomes more significant to influence the total cost. Additionally, the $\beta$ value indicates that when the tap water prices are $\$ 0.71 /$ ton and $\$ 1.00 /$ ton, a $1 \%$ increase of the process water recycling will reduce the total 
B. J. Wang et al. / Journal of Environmental Informatics 5 (2) 82 - 89 (2005)
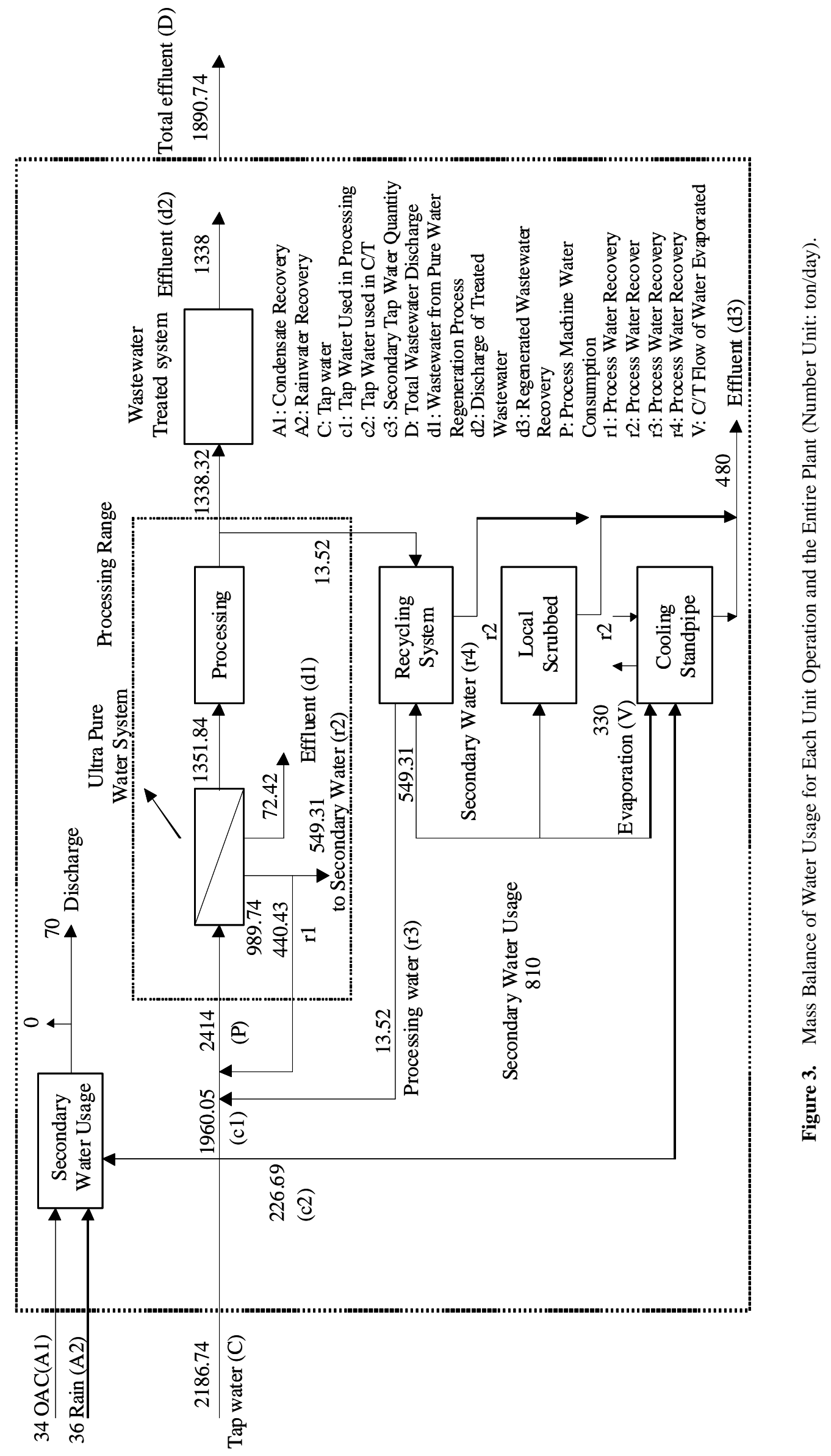

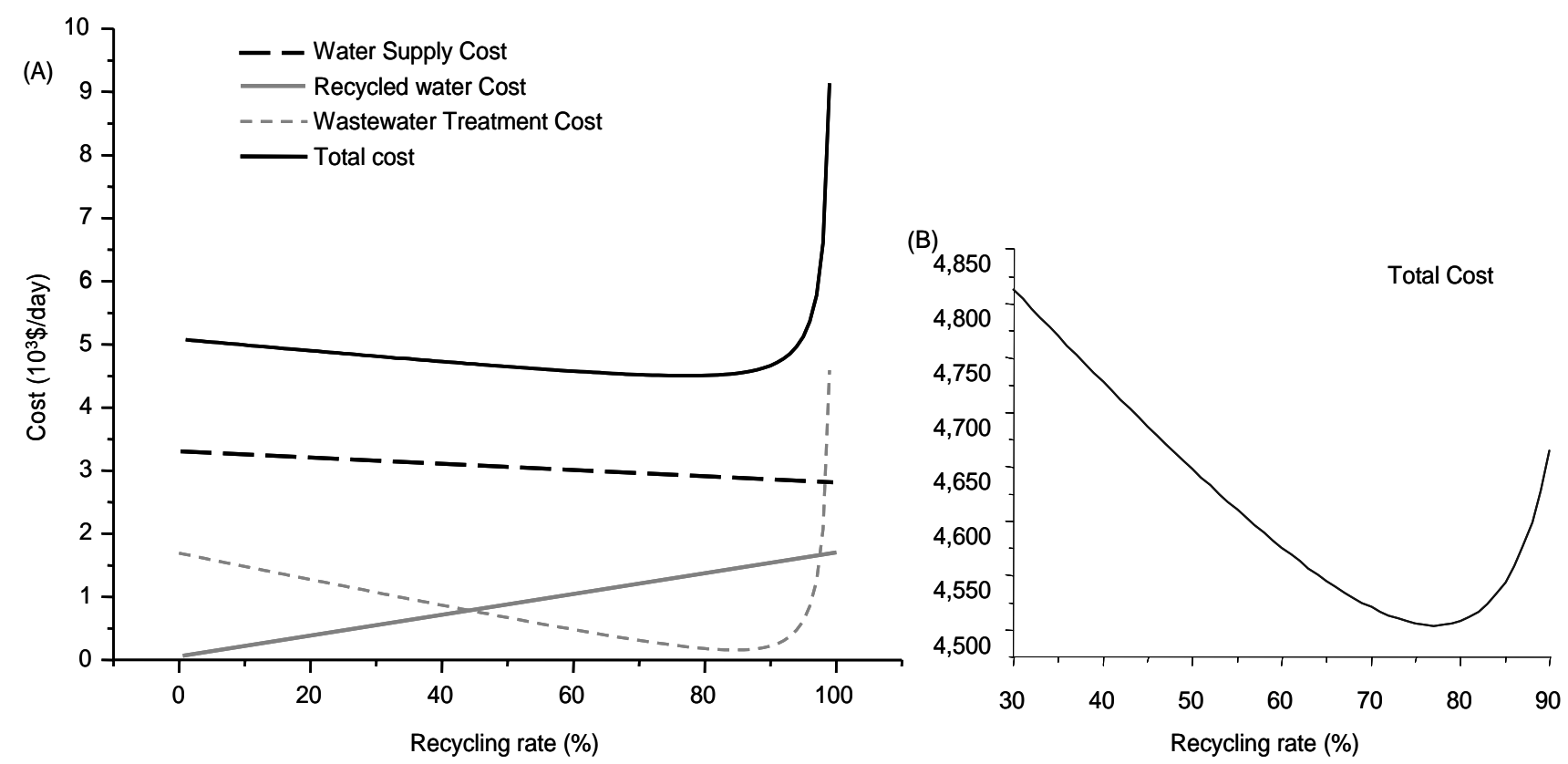

Figure 4. (A) Plot of Water Supply Cost, Wastewater Treatment Cost, Recycling Water Treatment Cost and Total Cost vs. Recycling Rate based on an Assumed Tap Water Cost of \$0.36 per ton; (B) Shows the Detailed Variation of the Total Cost Curve to Make the Minimum Total Cost More Obvious.

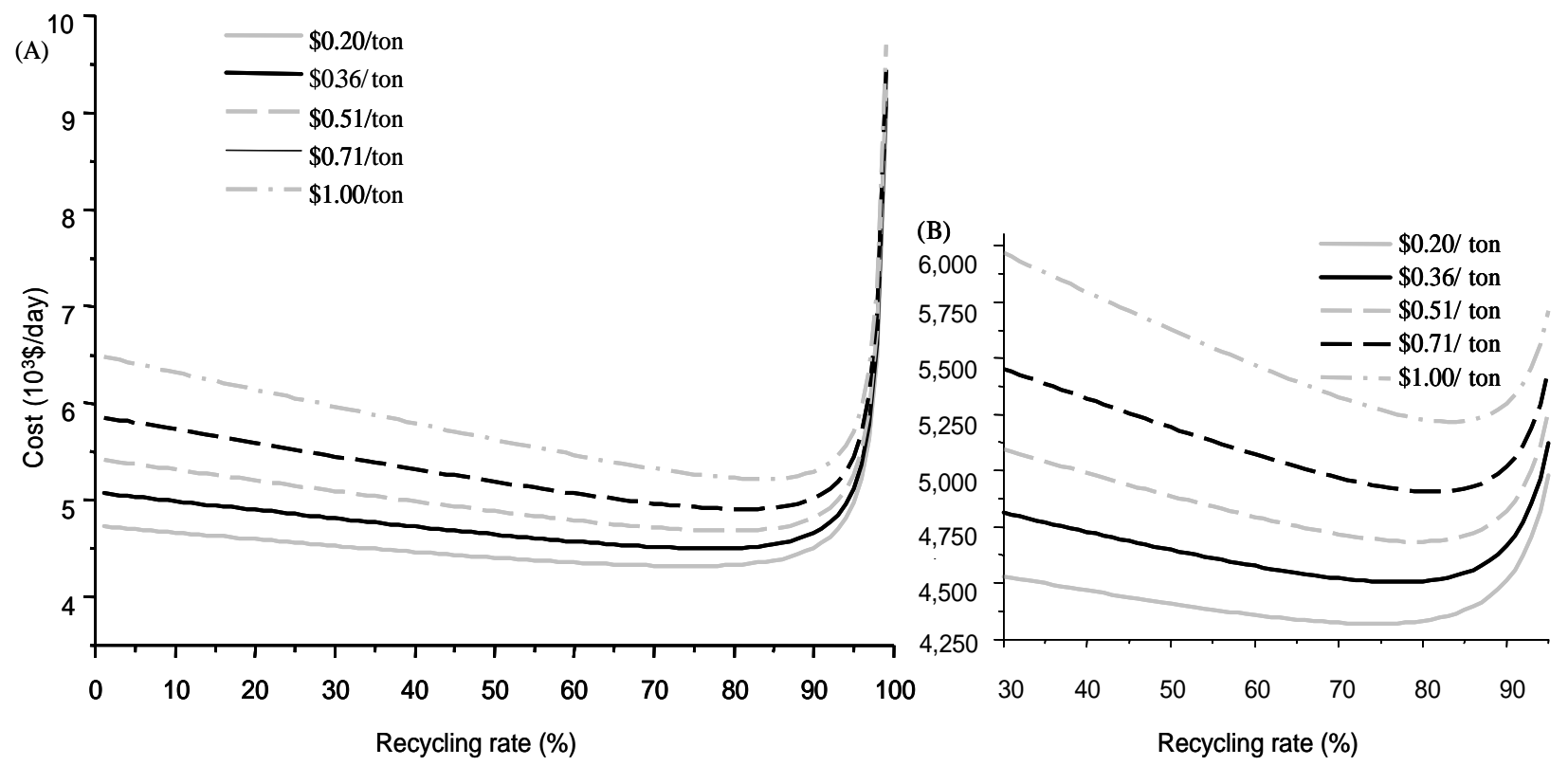

Figure 5. Plot of Total Cost vs. Recycling Rate under Various Tap Water Cost. 
wastewater treatment cost by $\$ 0.007 /$ ton and $\$ 0.012 /$ ton, respectively.

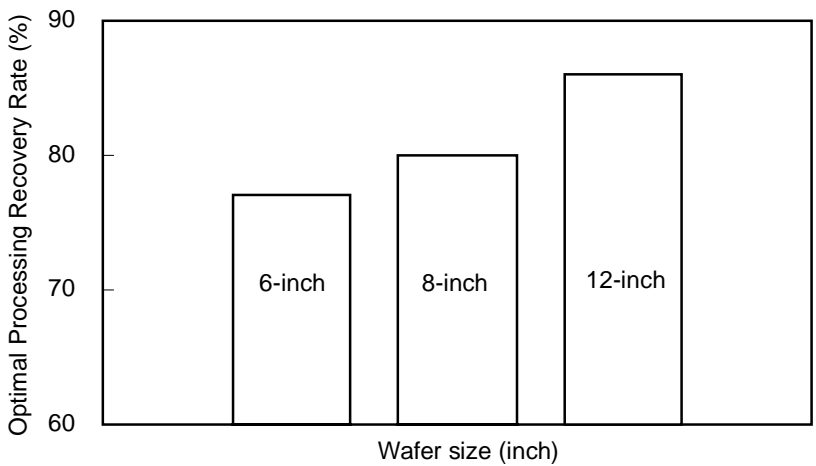

Figure 6. Optimal Water Recovery Rates for Different Wafer Sizes (tap water price: \$ 0.36/ton).

\section{Conclusions}

In this paper, optimal process water recycling for achieving the most cost-effective operation of the wafer manufacturing plant based on combined mass balance and cost analyses are presented. The results indicate that there are optimal process water recycling rates to achieve the most cost-effective operation of the semiconductor wafer plant. For the current tap water cost of $\$ 0.36 /$ ton, the optimal process water recycling rate of $77 \%$, higher than the current rate of $66 \%$ being implemented, will yield the most cost-effective process. At rising tap water costs, the optimal process recovery rate is shifted to higher levels. For example, the optimal recycling rate is $74 \%$ for $\$ 0.20 /$ ton and $84 \%$ for $\$ 1.00 /$ ton. Larger wafer diameters also cause higher optimal recycling rate; the optimal process water recycling rates for 6-inch, 8-inch and 12-inch wafer operations are 77\%, 81\% and $86 \%$, respectively. The significance of the results has been further confirmed by performing regression analyses.

\section{References}

Chen, R.C. (2002). Challenge on water usage technology faced by Taiwan's Hi-Tech industries, Taiwan (ROC) MOE Water Resources Agency, Water Savings Quarterly, 28. http://www.wcis.itri.org.tw/library/quarterly-2002.asp.

DeGenova, J. and Shadman, F. (1997). Recovery, reuse, and recycling of water in semiconductor wafer fabrication facilities. Environ. Prog., 16(4), 263-267.

Lin, J.C. (1999). Precious water for Taiwan's silicon processing, Taiwan (ROC) MOE Water Resources Agency, Water Savings Quarterly, 15. http://www.wcis.itri.org.tw/library/quarterly-1999.asp.

Lu, W.C. (1998). Introduction to water savings for semiconductor industry, Taiwan (ROC) MOE Water Resources Agency, Water Savings Quarterly, 11. http://www.wcis.itri.org.tw/library/quarterly-1998.asp.

Liu, R.X., Kuang, J., Gong, Q. and Hou, X.L. (2003). Principal component regression analysis with SPSS. Comput. Methods Programs Biomed., 71, 141-147.

Golden, J.H., Small, R., Pagan, L., Shang, G.C. and Ragavan, S. (2000). Evaluating and treating CMP wastewater. Semiconductor Int., 23, 85-98.

Michael, C.L. (1996). Ultra-pure water: the real cost. Solid State Technol., September, 70-75.

Ramalho, R.S. (1977). Introduction to wastewater treatment processes, John Wiley \& Sons, New York.

Taiwan (ROC) MOE Bureau of Industrial Development (2001). Pollution Prevention for Semiconductor Manufacturing Industry.

Thomas, S.R. and Thomas, W.P. (1996). Reducing DI water use. Solid State Technol., December, 78-87.

Shi, Y.H., Lin, H.D. and Yen, C.H. (2003). Development and Water Demand for Integrated Circuit and Color Imaging Industries, Taiwan (ROC) MOE Water Resources Agency. Water Savings Quarterly, 29.

http://www.wcis.itri.org.tw/library/quarterly-2003.asp.

World Semiconductor Trade Statistics (1998). Semiconductor Industry Blue Book, Price Waterhouse Coopers and Tohmatsu \& Co., San Jose, California.

You, S.H., Tseng, D.H., Guo, G.L. and Yang, J.J. (1999). The potential for the recovery and reuse of cooling water in Taiwan. Resour. Conserv. Recycl., 26, 53-70. 